District Asylum, Londonderry. - Female : Bessie Green.

The following is a list of the written questions:-1. What bones form the elbow joint? 2. What is a "Voluntary" muscle? Describe its structure and function, and give an example. 3. State the names and relative positions of the larger organs contained in the Cavities of the Thorax and Abdomen. 4. What are the functions of (a) Motor and (b) Seneory nerves ? 5. A patient has cut his wrist severely. What measures would you employ to stop the bleeding, and what would be your first step ? 6. In what form of insanity does refasal of food generally appear as a symptom? 7. What are the special precantions to be taken in a case of General Paralysis ? 8. To pre. vent acoidents what rules should be followed in the bathing of patients? 9. What precantions should an Attendant take on being sent to have charge of a patient in a private house ? 10. On what points should an Attendant in charge be prepared to make a daily report regarding a patient's progress ?

The next examination will be held on Monday, the lst day of November, 1897, and candidates are earnestly requested to send in their schedules duly filled up to the Registrar of the Association not later than Monday, the 4th day of October, 1897, a this is the last day apon which, under the rules, applications for examination can be received.

Examination for the Certificate in Psychological Medicine.

The next examination will be held on Thursday the 15th day of Jnly, 1897, at 10 a.m., in London at Bethlem Hospital; in Edinburgh at the Royal Asylum, Morningside ; in Glasgow at the Royal Asylum, Gartnavel; in $\Delta$ berdeen at the Royal Asylum ; and in Dablin at the Richmond Asylum.

The Gaskell Prize.

The examination for the Gaskell Prize will take place at the Bethlem Hospital, London, on Friday, July 16th, 1897, at 10 a.m.

Applications for admission to these examinations should be sent not later than Tharsday, July 8th, 1897, to the Registrar of the Association.

For further particulars respecting the varions examinations of the Association apply to the Registrar, Dr. Spence, Burntwood Asylum, near Lichfield.

\title{
NOTICES OF MEHTINGS.
}

\section{MRDICO-PBYCHOLOGICAL ABBOCIATION.}

Annual Meeting.-The Annual Meeting will be held in the College of Medicine, Newcastle-on-Tyne, on 29th and 30th July, 1897. There will probably be Excursions on the 31st July.

South.Western Division.-The Autumn Meeting will be held at Brislington House, Bristol, on Tuesday, 26th October, 1897.

Scottish Division.-The Autumn Meeting will be held as nsual on the second Thursday of Norember.

\section{APPOINTMENTS,}

Havelocx, Johy G., M.D.Edin., appointed Phy sioian-Superintendent to the Royal Asylum, Sunnyside, Montrose.

Howdre, JaYrs C., M.D., appointed Consulting Physician to the Royal Asylum, Sunnyside, Montrose.

SkINNER, W. A., M.B., C.M.Edin., appointed Junior Assistant Medical Officer to the Royal Asylum, Montrose. 